\title{
The Effects of Transition from Bedtime to Morning Glargine Administration in Patients with Poorly Regulated Type 1 Diabetes Mellitus: Croatian Pilot Study
}

Marina Gradiser · Ines Bilic-Curcic · Boris Djindjic · Maja Cigrovski Berkovic

To view enhanced content go to www.diabetestherapy-open.com

Received: August 5, 2015 / Published online: September 14, 2015

(C) The Author(s) 2015. This article is published with open access at Springerlink.com

\section{ABSTRACT}

Introduction: The objective of this study was to compare differences in glucoregulation, frequency of hypoglycemic episodes, glucose variability and lipid profiles of inpatients with poorly regulated type 1 diabetes mellitus (T1DM) after evening versus morning glargine application.

Methods: Eighteen patients with poorly regulated T1DM, glycated hemoglobin (Hba1c)

Electronic supplementary material The online version of this article (doi:10.1007/s13300-015-0130-2) contains supplementary material, which is available to authorized users.

\section{Gradiser}

Department of Internal Medicine, General Hospital Čakovec, 40000 Čakovec, Croatia

\section{Bilic-Curcic $(\bowtie)$}

Department of Pharmacology, Faculty of Medicine, University of Osijek, University Hospital Center Osijek, 31000 Osijek, Croatia

e-mail: ibcurcic@mefos.hr

B. Djindjic

Institute of Pathophysiology, School of Medicine, University in Nis, 18000 Nis, Serbia

M. C. Berkovic

Clinical Department of Diabetes, Endocrinology and Metabolism Disorders, University Hospital Centre "Sestre Milosrdnice", 1000 Zagreb, Croatia levels $\geq 7 \%$ and frequent nocturnal and/or morning hypoglycemic episodes were included in this study. There was a 12-week screening phase where patients continued their usual insulin regimen and were encouraged to achieve optimal glycemic control; however, all patients maintained HbA1c values $\geq 7 \%$ and continued to have frequent nocturnal and/or morning hypoglycemic events and were therefore transitioned to morning application of insulin glargine for 12 weeks. The primary outcome was to investigate changes in HbA1c values 12 weeks after the transition. The secondary outcome was to evaluate the effect of transition on glucose variability, incidence of hypoglycemic episodes, insulin doses, lipid profile and weight. Data were analyzed using paired Student's t test and Pearson correlation.

Results: After the transition, there was no significant change in total daily dose of basal insulin ( $p$ 0.114) and the average body weight remained unchanged, while significant reduction of $\mathrm{HbA1c}$ was present $(8.02 \pm 0.5$ vs. $7.4 \pm 0.3 \%)(p<0.01)$ resulting in a decrease in nocturnal and daytime hypoglycemic episodes per month per person $(p<0.01)$. Parameters of glucose variability (glycemic standard 
deviations and J-index) were also improved after transition period $(p<0.01)$. As for the lipid profile, increase of high-density lipoprotein cholesterol and decrease of triglycerides $(p<0.01)$ were noticed, while other lipid parameters remained unaffected. Furthermore, insignificant association of basal insulin dose with HbA1c values regardless of the time of administration was observed.

Conclusion: In patients with poorly regulated T1DM, transition to morning application of glargine improved glucoregulation (including a decrease in HbA1c, glucose variability and number of nocturnal hypoglycemic episodes), followed by favorable changes in lipid profile without affecting body weight. These effects were associated with the time of application, but not with the insulin dose.

Keywords: Basal insulin; Diabetes type 1; Glucoregulation; Hypoglycemia; Lipid profile; Morning administration

\section{INTRODUCTION}

The average individual with type 1 diabetes mellitus (T1DM) experiences about two episodes of symptomatic hypoglycemia per week [1]. Severe hypoglycemia (requiring help for recovery) has an annual prevalence of $30-40 \%$ and an annual incidence of $1.0-1.7$ episodes per patient per year [1]. This risk is increased markedly with the strict glycemic control and leads to impaired quality of life.

There have only been a small number of studies performed on patients with T1DM evaluating whether the timing of insulin glargine administration (morning or bedtime) would affect glucoregulation and/or frequency of hypoglycemic episodes [2, 3]. Results obtained from those studies indicated that there was no difference in glycated hemoglobin (HbA1c) values regarding the time of administration, although nocturnal hypoglycemias were less frequent in a group who administered glargine in the morning [2, 3]. The objective of this prospective observational study was to investigate whether the transition from bedtime to morning insulin glargine administration has a beneficiary effect on glucose regulation and hypoglycemic episodes as well as lipid profiles in patients with poorly regulated T1DM.

\section{PATIENTS AND METHODS}

A total of 18 patients with poorly controlled T1DM were recruited for this pilot study during routine outpatient visits (from County Hospital Cakovec, University Hospital Center Osijek and University Hospital Center "SestreMilosrdnice" Zagreb). In this observational longitudinal study, 18 patients (9 females, 9 males) that had been treated with an intensified insulin regimen (glargine at bedtime (09:00 or 10:00 p.m.) + lispro/aspart/glulisine prior to meals) for at least 1 year with an average Hba1c value $\geq 7 \%$, frequent nocturnal and/or morning hypoglycemic episodes and high pre-dinner BG (blood glucose) values $(\geq 7.1 \mathrm{mmol} / \mathrm{L})$ were directly switched to morning administration (09:00 or 10:00 a.m.) of insulin glargine injection. The basal insulin was titrated using a simple algorithm seeking a target fasting plasma glucose $\leq 5.5 \mathrm{mmol} / \mathrm{L}$, while dosages of short acting insulin were calculated according to carbohydrates and pre-meal BG values. Prior the transition of glargine administration, there was a 12-week screening phase where patients continued their 
usual insulin regimen and were encouraged to achieve optimal glycemic control. Patients were also instructed to obtain 4-point and 8-point BG values determined by self-monitoring $B G$ (SMBG). In addition, frequencies of hypoglycemic events were assessed using standard patient diaries. Frequent hypoglycemia was defined as approximately two to four times per week or more, nocturnal hypoglycemia applied to hypoglycemic events from bedtime to 06:00 a.m. whereas morning hypoglycemia encompassed all events from 06:00 a.m. until breakfast [4]. Hypoglycemic episodes were defined as events with symptoms consistent with hypoglycemia in which the patient had a BG level $<3.9 \mathrm{mmol} / \mathrm{L}$ or the event was associated with prompt recovery after oral carbohydrate or intravenous glucose or subcutaneous glucagon administration and required another person's assistance (severe hypoglycemic episode). In addition, all events that were not accompanied by typical symptoms of hypoglycemia but a measured plasma glucose concentration was $\leq 3.9 \mathrm{mmol} /$ $\mathrm{L}$ were included [4]. At the end of the 12-week screening period, HbA1c levels and lipid profiles were determined. SMBG values and patient diaries were also assessed. All patients included at the screening phase maintained poor regulation of diabetes with an $\mathrm{HbA1c}$ level $\geq 7 \%$ (mean value $8.02 \pm 0.5 \%$ ). They also continued to have frequent nocturnal and/or morning hypoglycemic events and were therefore transitioned to morning application of insulin glargine. The primary objective was to investigate changes in HbA1c values 12 weeks after the transition (the end point). The secondary objective was to evaluate the effect of transition on glucose variability, incidence of hypoglycemia, insulin doses, lipid profile and weight.

\section{Statistical Analysis}

Results were analyzed using descriptive statistical analysis. Continuous variables were summarized using sample size, mean and standard deviation values. Significance was declared at a two-sided 0.01 level, unless otherwise specified. The difference between continuous variables at the beginning and at the end of observation was analyzed by paired student's $t$ test for parametric analysis, while Wilcoxon signed ranks test was used for nonparametric analysis (both were used for comparison of hypoglycemic events). Pearson's correlation coefficients were computed to estimate the magnitude of the association between variables of interest. Statistical analyses were performed using SPSS software for Windows (version 16.0, SPSS Inc., Chicago IL, USA).

\section{Compliance with Ethics Guidelines}

All procedures followed were in accordance with the ethical standards of the responsible committee on human experimentation (institutional and national) and with the Helsinki Declaration of 1964, as revised in 2013. Informed consent was obtained from all patients for being included in the study.

Additional informed consent was obtained from all patients and their identifying information is included in this article.

\section{RESULTS}

A total number of 18 patients with T1DM were analyzed. Patients' average age was $33.1 \pm 9.1$ years and the average duration of diabetes was $19.7 \pm 12.0$ years on intensified therapy with insulin analogs. Table 1 shows a 
Table 1 Characteristics of the subjects at baseline, at transition and 12 weeks after the transition

\begin{tabular}{|c|c|c|c|}
\hline Variable & $\begin{array}{l}\text { Baseline ( } 12 \text { week before } \\
\text { transition) }\end{array}$ & At transition & $\begin{array}{l}12 \text { weeks after } \\
\text { transition }\end{array}$ \\
\hline HbAlc (\%) & $8.02 \pm 0.60$ & $8.08 \pm 0.57$ & $7.45 \pm 0.38^{\dagger *}$ \\
\hline Fasting BG (mmol/L) & $4.78 \pm 0.60$ & $4.64 \pm 0.66$ & $6.25 \pm 0.31^{\dagger *}$ \\
\hline Postprandial BG (mmol/L) & $6.76 \pm 0.80$ & $6.65 \pm 0.75$ & $6.56 \pm 0.57$ \\
\hline Pre-lunch BG (mmol/L) & $7.41 \pm 0.80$ & $7.40 \pm 0.81$ & $6.81 \pm 0.46^{\dagger *}$ \\
\hline Pre-dinner BG (mmol/L) & $10.31 \pm 1.20$ & $9.84 \pm 0.74$ & $6.87 \pm 0.38^{\dagger *}$ \\
\hline $\operatorname{BMI}\left(\mathrm{g} / \mathrm{cm}^{2}\right)$ & $23.54 \pm 3.18$ & $23.54 \pm 3.18$ & $23.52 \pm 2.46$ \\
\hline Body weight (kg) & $70.33 \pm 15.21$ & $70.33 \pm 15.21$ & $70.10 \pm 13.93$ \\
\hline Total cholesterol $(\mathrm{mmol} / \mathrm{L})$ & $4.5 \pm 0.40$ & $4.37 \pm 0.52$ & $4.30 \pm 0.47$ \\
\hline Triglycerides $(\mathrm{mmol} / \mathrm{L})$ & $2.1 \pm 0.60$ & $1.93 \pm 0.50^{*}$ & $1.72 \pm 0.37^{\dagger *}$ \\
\hline $\mathrm{HDL}(\mathrm{mmol} / \mathrm{L})$ & $1.01 \pm 0.09$ & $1.07 \pm 0.17$ & $1.20 \pm 0.10^{\dagger *}$ \\
\hline $\mathrm{LDL}(\mathrm{mmol} / \mathrm{L})$ & $3.30 \pm 0.40$ & $3.14 \pm 0.44$ & $3.07 \pm 0.44$ \\
\hline Daily dose of basal insulin (IU) & $24.60 \pm 6.60$ & $23.35 \pm 5.90$ & $24.24 \pm 6.96$ \\
\hline $\begin{array}{l}\text { Proportion of patients experienced morning } \\
\text { hypoglycemia }(n / \%)\end{array}$ & $18 / 100.0$ & $18 / 100.0$ & $11 / 61.0^{\mathrm{II}}$ \\
\hline $\begin{array}{l}\text { Proportion of patients experienced nocturnal } \\
\text { hypoglycemia }(n / \%)\end{array}$ & $12 / 66.6$ & $13 / 72.2$ & $5 / 27.7^{\mathrm{II}}$ \\
\hline $\begin{array}{l}\text { Average number of morning hypoglycemias per } \\
\text { month per patient }\end{array}$ & $4.30 \pm 1.60$ & $3.66 \pm 1.40^{*}$ & $0.63 \pm 0.74^{\$ *}$ \\
\hline $\begin{array}{l}\text { Average number of nocturnal hypoglycemias per } \\
\text { month per patient }\end{array}$ & $0.70 \pm 0.60$ & $0.69 \pm 0.51$ & $0.22 \pm 0.39^{\S *}$ \\
\hline Total number of morning hypoglycemias & 78 & 66 & $12^{* \dagger}$ \\
\hline Total number of nocturnal hypoglycemias & 13 & 13 & $4^{* \dagger}$ \\
\hline
\end{tabular}

$H b A 1 c$ glycated hemoglobin, $B G$ blood glucose, $B M I$ body mass index, $H D L$ high-density lipoprotein, $L D L$ low-density lipoprotein, $I U$ international unit

Paired Student's $t$ test; ${ }^{*} p<0.01$ vs. baseline; ${ }^{\dagger} p<0.01$ vs. transition; Wilcoxon Signed Ranks Test; ${ }^{\ddagger} p<0.01$ vs. baseline; ${ }^{\S} p<0.01$ vs. transition; Fisher exact test; ${ }^{\text {II }} p<0.01$ vs. transition

comparison of the data obtained at baseline, at transition and at 12 weeks after the transition. A significant reduction of mean $\mathrm{HbA1c}$ values from baseline to end point was observed $(8.02 \pm 0.60 \quad$ vs. $\quad 7.45 \pm 0.38 \%, \quad p<0.01)$. Regarding glycemic control based on SMBG values (4 point and 8 point), a decrease in pre-lunch $(p<0.01)$ and pre-dinner $(p<0.01)$ $B G$ values were registered, accompanied with an increase in fasting glycemia $(p<0.01)$. A total daily dose of basal insulin analog remained unaffected $\quad(23.35 \pm 5.90$ vs. $24.24 \pm 6.96$ international units $p=0.114$ ) when compared to initial dose as well as body weight and body mass index. Furthermore, the proportion of patients experiencing morning and nocturnal hypoglycemic events was significantly decreased at the end of a 12-week period after 
transition $(p<0.01)$. The average number of morning and nocturnal hypoglycemic episodes per month per patient and total number of overall hypoglycemic events were also significantly reduced $(p<0.01)$. Significant changes regarding lipid profiles were also observed such as an increase of high-density lipoprotein cholesterol $\quad(1.07 \pm 0.17 \quad$ vs. $1.20 \pm 0.10 \mathrm{mmol} / \mathrm{L}, p<0.01)$ and decrease of triglyceride levels $\quad(1.93 \pm 0.50 \quad$ vs. $1.72 \pm 0.37 \mathrm{mmol} / \mathrm{L}, p<0.01$ ), while total and low-density lipoprotein cholesterol levels were not changed (Table 1).

\section{DISCUSSION}

Former studies investigating the effect time of administration in patients with T1DM demonstrated a similar reduction in HbA1c with morning and bedtime insulin glargine dosages as the present study [2, 3]; however, those studies showed no significant difference in the frequency or duration of hypoglycemia during the day or the night irrespective of the timing of glargine injection [3]. In the present study, a significant reduction of $\mathrm{HbA1c}$ was registered at 12 weeks after initial transition, without changes in insulin doses and with lower rates of hypoglycemic episodes (especially in the morning). Decrease in pre-lunch and pre-dinner BG values and an increase in fasting glycaemia were also observed. This suggests that an improvement of overall glycemic control was achieved due to a decrease of glucose variability regardless of higher fasting BG values. Since glucose fluctuation is a well-recognized glycemic disorder next to hyperglycemia both fasting and postprandial and is held accountable for excessive glycation and generation of oxidative stress, its decrease could potentially have an important impact on development of chronic complications [5].

Recently, Porcellati et al. demonstrated that the pharmacodynamics of insulin glargine differs depending on time of administration. The 24-h glucose infusion rate area under the curve (AUC [0-24 h]) was similar in evening and morning studies; however, morning administered insulin activity was greater in the first $0-12 \mathrm{~h}$, while with evening administration the activity was greater in the $12-24$-h period following dosing in patient with type 2 diabetes mellitus [6]. It was speculated that these results could reflect the impact of circadian changes in insulin sensitivity in type 2 diabetes (lower in the night-early morning). The question remains as to whether the same explanation could be applied to patients with T1DM in the present study. The variability of the dawn phenomenon is an individual characteristic and should be considered prior to reaching any therapeutic decisions aimed at correcting fasting hyperglycemia [7]. Obviously, increases in bedtime doses of hypoglycemic agents may correct early morning hyperglycemia but may also be associated with undesirable nocturnal and early morning hypoglycemia as well as reactive hyperglycemia during the daytime leading to overall poor glycemic control and acute glucose fluctuations.

The present study has several limitations. The number of subjects was small and the treatment period short. It is also an observational study and thus potentially biased since study effect cannot be excluded although there was a 3-month run in period with strict self control. A large-scale, long-term randomized clinical study is required for confirmation of the present results. 


\section{CONCLUSION}

In summary, transition from bedtime to morning basal insulin administration in patients with poorly regulated T1DM could possibly improve glucoregulation and reduce the number of nocturnal and morning hypoglycemic episodes without affecting body weight, while at the same time inducing favorable changes in glucose variability and lipid profile. The effect on glycemic control was not associated with insulin dose but only with the time of basal insulin application.

\section{ACKNOWLEDGMENTS}

No funding or sponsorship was received for this study or publication of this article.

All named authors meet the International Committee of Medical Journal Editors (ICMJE) criteria for authorship for this manuscript, take responsibility for the integrity of the work as a whole, and have given final approval to the version to be published.

This research was funded by authors.

Conflict of interest. Marina Gradiser, Ines Bilic-Curcic, Boris Djindjic and Maja Cigrovski Berkovic declare no conflict of interest.

Compliance with ethics guidelines. All procedures followed were in accordance with the ethical standards of the responsible committee on human experimentation (institutional and national) and with the Helsinki Declaration of 1964, as revised in 2013. Informed consent was obtained from all patients for being included in the study.

Additional informed consent was obtained from all patients and their identifying information is included in this article.
Open Access. This article is distributed under the terms of the Creative Commons AttributionNonCommercial 4.0 International License (http://creativecommons.org/licenses/by-nc/ 4.0/), which permits any noncommercial use, distribution, and reproduction in any medium, provided you give appropriate credit to the original author(s) and the source, provide a link to the Creative Commons license, and indicate if changes were made.

\section{REFERENCES}

1. Frier BM. The incidence and impact of hypoglycemia in type 1 and type 2 diabetes. Int Diabetes Monit. 2009;21:210-8.

2. Hamann A, Matthaei S, Rosak C, Silvestre L, HOE901/ 4007 Study Group. A randomized clinical trial comparing breakfast, dinner, or bedtime administration of insulin glargine in patients with type 1 diabetes. Diabetes Care. 2003;26(6):1738-44.

3. Şimşek DG, Yıldız B, Asarand G, Darcan S. A randomized clinical trial comparing breakfast and bedtime administration of insulin glargine in children and adolescents with type 1 diabetes. J Clin Res Pediatr Endocrinol. 2008;1(1):15-20. doi:10.4008/ jcrpe.v1i1.10.

4. Seaquist ER, Anderson J, Childs B, Cryer $P$, Dagogo-Jack S, Fish L, et al. Hypoglycemia and diabetes: a report of a workgroup of the American Diabetes Association and the Endocrine Society. Diabetes Care. 2013;36(5):1384-95. doi:10.2337/ dc12-2480.

5. Monnier L, Colette C. Glycemic variability: should we and can we prevent it? Diabetes Care. 2008;31(Suppl 2):S150-4.

6. Porcellati F, Lucidi P, Cioli P, Candeloro $\mathrm{P}$, MarinelliAndreoli A, Marzotti $\mathrm{S}$, et al. Pharmacokinetics and pharmacodynamics of insulin glargine given evening as compared with morning in type 2 diabetes mellitus. Diabetes Care. 2014;38(3):503-12. doi:10.2337/dc14-0649.

7. Carroll MF, Schade DS. The dawn phenomenon revisited: implications for diabetes therapy. EndocrPract. 2005;11(1):55-64. 